inflammatory bowel disease, psoriasis or Reiter's syndrome) were studied. [Mean (SD) age at onset: 23.3 years $(7 \cdot 46)$ and mean (SD) disease duration: $23 \cdot 0$ years $(12 \cdot 78)$ ]. Five ( 4 female, 1 male) had peripheral joint disease.

Interleukin-6 concentrations were compared with a modified Disease Activity Index (DAI), ${ }^{4}$ early morning stiffness (EMS), current age, age at onset, disease duration and the APRs.

To determine IL-6 concentrations, anticoagulated venous blood samples from 50 patients were collected at a tertiary referral centre and centrifuged immediately at $1000 \times \mathrm{g}$ for 10 minutes. The plasma was subsequently stored at $-20^{\circ} \mathrm{C}$ until used for the assay. The 'IL-6 IRMA' (immunoradiometric assay) kit was used for determining IL-6 concentrations. (Control values $<6 \mathrm{pg} / \mathrm{ml}$, supplied by Medgenix Diagnostics, Brussels, Belgium).

PV (normal 1.50-1.72 mPAS) and ESR (Westergren; normal $<15 \mathrm{~mm} /$ hour) were determined as were CRP levels by enzymelinked immuno-absorbent assay (normal $<0.01 \mathrm{~g} / \mathrm{l}$ ). Statistical assessments were carried out using Chi-squared or Pearson productmoment correlations.

Forty three of 50 patients ( $86 \%$ ) had IL-6 concentrations $>6 \mathrm{pg} / \mathrm{ml}$. This involved $84 \%$ of the males, all females and all patients with peripheral joint involvement; whereas the number with abnormal ESR, PV and CRP results were $57,44,40 \%$ respectively (figure). As shown, the mean and 1 SD figures are only above the normal cut off point for IL-6.

When the DAI of 43 patients was analysed it was found that six had low, 28 moderate and nine high disease activity. (DAI: $<14=$ low, $14-23=$ moderate, $24-32=$ high). The mean IL-6 values for each group were $13 \cdot 2,16 \cdot 0$ and 17.6 respectively. Correlations of the DAI with IL-6, the APRs, age (current and at onset) and duration of disease were all non significant.

Correlations between IL- 6 and the APRs, age (current and at onset) plus disease and morning stiffness duration were all non significant. EMS correlated with ESR only $(p=0.02)$.

One patient developed uveitis while being treated as an inpatient. The levels of IL- 6 did

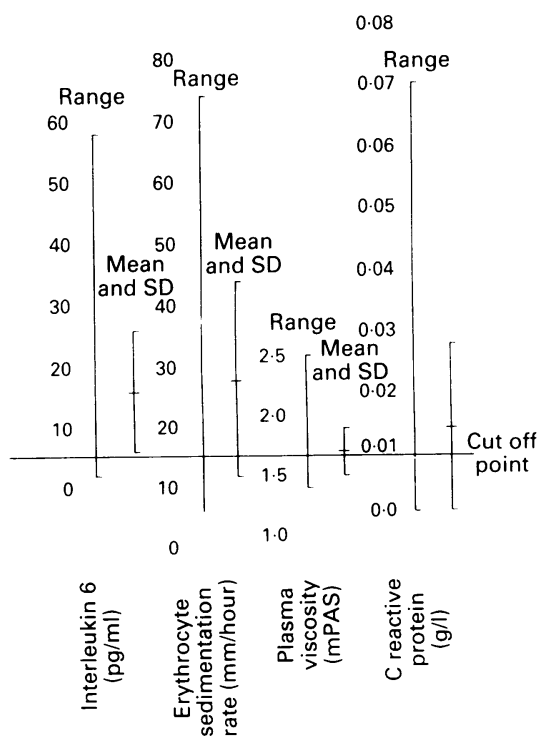

Values for IL-6, ESR, PV and CRP with distribution of results, mean and one standard deviation. Horizontal bar relates to normal cut off values. not alter significantly before or after the flare up (51.7 and $43.9 \mathrm{pg} / \mathrm{ml}$ respectively). There were no clinical correlates found for those with high levels of IL-6 compared with those with low levels.

Increased serum concentrations of IL-6 have been described in patients with inflammatory disorders such as RA, Crohn's disease $^{5}$ and other conditions including major surgery," severe burns ${ }^{\bar{\gamma}}$ and bacterial infections. ${ }^{8}$ IL-6 is said to be the major cytokine responsible for APR production by the liver."

Our data revealed that circulating concentrations of IL- 6 were increased in the majority $(86 \%)$ of patients with AS. By contrast abnormal values of ESR, PV and CRP were found in only 57, 44 and $40 \%$ respectively. Clearly, IL-6 is a more sensitive 'marker' for AS than the APRs. However, there was no correlation between IL-6 and any of the clinical variables. There was no relationship between IL-6 and the APRs.

This was a cross-sectional study to assess the levels of IL-6 in patients with AS with reference to a previously defined 'normal' level in an unmatched control population. As this study has not produced any biological explanation for the results further studies are required. It would be useful to know how IL-6 varies over time, with treatment and during flares in the disease.

There appears to be at least one laboratory variable that is raised in the clear majority of patients with AS in contrast to ESR, PV or CRP.

We thank the Arthritis and Rheumatism Council for Great Britain, the National Ankylosing Spondylitis Society, the Coates Trust and the Pilkington Trust for their financial support; also Jean Wright and Trish Myers for their secretarial assistance

Z N TUTUNCU A BILGIE L G KENNEDY A CALIN

Royal National Hospital for Rheumatic Diseases
Bath

Correspondence to Dr Andrei Calin, Royal National Hospital for Rheumatic Diseases, Upper Borough Walls, Bath BAl 1RL, United Kingdom

1 Houssieu F A, Devogelaer J P, van Damme J, Deuxchaisnes $C$, van Snick J. Interleukin-6 in synovial fluid and serum of patients with rheumatoid arthritis and other inflammatory arthritides. Arth Rheum 1988; 31: 784-8.

2 Sawada T, Hirohata S, Inoue T, Ho K Correlation between rheumatoid factor and IL-6 activity in synovial fluids from patients with rheumatoid arthritis. Clin Expt Rheum 1991; 9: 363-8.

3 Will R, Magaro L, Elswood J, Calin A. Ankylosing spondylitis (AS) and acute phase reactants (APRs). The elusive relationship. Brit f Rheum 1989; 26 (S2): 11.

4 Kennedy L G, Edmunds L, Calin A. The natural history of ankylosing spondylitis. natural history of ankylosing spondylitis. Does it

5 Gross V, Andus T, Caesar I, Roth M Scholmerich J. Evidence for continuou stimulation of interleukin-6 production in Crohn's disease. Gastroent 1992; 102: 514-9.

6 Nishimoto N, Yoshizaki $\mathrm{K}$, Tagoh $\mathrm{H}$, et al. Elevation of serum interleukin-6 prior to acute phase proteins on the inflammation by surgical operation. Clin Immunol Immunopathol 1989; 50: 399-401.

7 Nijsten $M$ W, de Groot E R, Ten Duis $H$ J, Klesen H J, Hack C E, Aarden L A. Serum levels of interleukin- 6 and acute phase responses (letter). Lancet 1987; 2: 921 .

8 Waage A, Brandtzaeg P, Halstensen A, Kierulf P, Espevik T. The complex pattern of Kierulf $P$, Espevik $T$. The complex pattern of cytokines in serum from patients with meningococcal septic shock. Association between interleukin-6, interleukin 1 and
9 Koj A. Definition and classification of acute phase proteins. In: Gordon A H, Koj A, eds. The acute phase response to injury and infection. Amsterdam: Elsevier, 1985: 139-232.

\section{HLA antigens in Japanese patients with high titre anti-ribonucleoprotein antibodies}

Antibodies to nuclear ribonucleoprotein (nRNP) have been proposed as characteristic of a distinct autoimmune disease, mixed connective tissue disease (MCTD).' Previous reports have shown some correlations between genetic factors and MCTD in white groups. ${ }^{2}$ However, studies on HLA antigens in Japanese patients with MCTD remain controversial. ${ }^{3}+$ We studied 36 Japanese patients who had anti-nRNP antibodies at high titres to find an association between HLA antigens and autoantibody production.

Thirty six unrelated Japanese patients who had anti-nRNP antibodies at high titres $(\geq 1: 10240)$ were studied. All were women and their mean (SD) age was $37.9(11.8)$ years. Thirty two patients fulfilled the criteria for systemic lupus erythematosus (SLE) ${ }^{5}$ and the other four were diagnosed as having MCTD according to the disease criteria by Kasukawa et al. ${ }^{\circ}$ Twenty four patients had anti-Sm antibodies and twelve did not. All had been suffering from Raynaud's phenomenon. The patients were divided into two groups, one with anti-Sm antibodies (group $A, n=24$ ) and the other without antiSm (group $B, n=12$ ). The mean age, the mean duration of the disease and the mean titre of anti-nRNP were not statistically different between the two groups (data not shown). Titres of anti-nRNP and anti-Sm antibodies were detected by passive haemagglutinin test. HLA-A, B, C and DR typing was performed by using standard lymphomicrocytotoxicity method. Chi-square method was used for statistical analysis and the $p$ value was corrected for the number of antigens tested (pc).

Frequencies of HLA-A, B, C and DR antigens in 36 patients and 105 healthy controls are shown in the table. There were no apparent differences between the patient group and healthy controls. Although there were no significant differences between group $A$ and controls, a strong association with DR9 was observed in group B compared with normal controls $(83.3 \%$ v $32.7 \%$, pc $<0.05)$.

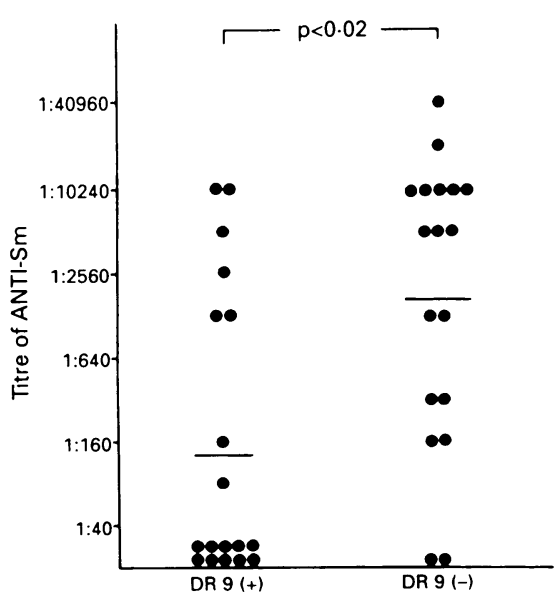

Anti-Sm antibodies in patients with or without HLA-DR9. 
Frequencies of $H L A-A, B, C$ and $D R$ antigens in patients with or without anti-Sm antibodies

\begin{tabular}{lccc}
\hline $\begin{array}{l}\text { HLA } \\
\text { antigens }\end{array}$ & $\begin{array}{l}\text { Group } A(\text { Sm }(+)) \\
\text { number }(\%)\end{array}$ & $\begin{array}{l}\text { Group } B(S m(-)) \\
\text { number }(\%)\end{array}$ & $\begin{array}{l}\text { Healthy controls } \\
\text { number }(\%)\end{array}$ \\
\hline A2 & $12(50 \cdot 0)$ & $7(58 \cdot 3)$ & $51(46 \cdot 4)$ \\
A24 & $15(62 \cdot 5)$ & $7(58 \cdot 3)$ & $60(54 \cdot 5)$ \\
Aw33 & $2(8 \cdot 3)$ & $0(0 \cdot 0)$ & $22(20 \cdot 0)$ \\
B7 & $3(12 \cdot 5)$ & $1(8 \cdot 3)$ & $9(8 \cdot 2)$ \\
B35 & $5(20 \cdot 8)$ & $2(16 \cdot 7)$ & $49(17 \cdot 3)$ \\
B40 & $13(54 \cdot 2)$ & $9(75 \cdot 0)$ & $40(34 \cdot 5)$ \\
C1 & $5(20 \cdot 8)$ & $1(8 \cdot 3)$ & $46(41 \cdot 8)$ \\
C3 & $14(58 \cdot 3)$ & $6(50 \cdot 0)$ & $31(28 \cdot 2)$ \\
DR2 & $8(33 \cdot 3)$ & $2(16 \cdot 7)$ & $47(42 \cdot 7)$ \\
DR4 & $11(45 \cdot 8)$ & $3(25 \cdot 0)$ & $36(32 \cdot 7)$ \\
DR9 & $8(33 \cdot 3)$ & $10(83 \cdot 3)^{\star}$ & $23(20 \cdot 1)$ \\
DR13 & $1(4 \cdot 2)$ & $1(8 \cdot 3)$ & \\
\hline
\end{tabular}

${ }^{\star} \mathrm{pc}<0.05$ compared with normal controls.

Next we evaluated the titres of anti-Sm antibodies between DR9 positive and negative patients. As shown in the figure, the mean titre of anti-Sm antibodies was higher in patients without DR9 (1:136 v 1:1741, $\mathrm{p}<0.02$ ) while titres of anti-nRNP were not significantly different between DR9 positive and negative groups (data not shown).

Antibodies to nRNP are frequently detected in sera from patients with MCTD as well as SLE, and at a low frequency, from other autoimmune disorders. ${ }^{7}$ Patients who have high titre anti-nRNP but not anti-Sm antibodies share some clinical signs, including Raynaud's phenomenon and swollen hands. They have overlapping features of SLE, polymyositis and scleroderma. ${ }^{1}$ The disease criteria for MCTD, however, has now been under discussion. ${ }^{8}$ Previous reports have shown some correlations between MCTD and DR4 in white groups. Genth et al found that DR4 was more frequent in patients with anti-nRNP antibodies than healthy controls. ${ }^{2}$ In Japanese, however, studies on HLA antigens in patients with MCTD revealed conflicting results. $^{34}$

We selected patients who had high-titre anti-nRNP antibodies. There were only four individuals who shared features of SLE, polymyositis, and scleroderma. Our aim was not to find an association between genetic factors and SLE or MCTD, but to clarify the pathogenesis involved in production of autoantibodies. In our 36 patients, although there was no association between the presence of certain class I or II antigens with either anti-nRNP nor Sm antibody production, there was a negative correlation between DR9 and anti-Sm antibodies. These results suggest that HLA-DR9 or a closely linked gene may predispose to the production of anti-nRNP and anti-Sm antibodies. Since the number of patients studied remains small, further studies will be needed to confirm our observation.

\section{TAKAKO KAWAI KENII TANI TAKAO OKUBO First Department of Internal Medicine HIROYO SUZUKI ATSUSHI OKAMURA \\ Third Department of Internal Medicine}

MUTSUHIKO MINAMI Department of Paracytology

KIYOSHI KATOH Department of Medical Information Yokohama City University School of Medicine Yokohama, Japan

Correspondence to: Takako Kawai, First Department of Internal Medicine, Yokohama City University School of Medicine, 3-46 Urafune-cho, Minami-ku, Yokohama 232 Japan.
1 Sharp G C, Irvin W S, Tan E M, Gould R G, Holman $H$ R. Mixed connective tissue disease-An apparently distinct rheumatic disease syndrome associated with a specific antibody to an extractable nuclear antigen (ENA). Am f Med 1972; 52: 148-59.

2 Genth E, Zarnowski H, Mierau R, Wohltmann D, Hartl P W. HLA-DR4 and $\operatorname{Gm}(1,3 ; 5,21)$ are associated with U1-nRNP antibody positive connective tissue disease Ann Rheum Dis 1987, 46: 189-96.

3 Sasazuki T, Kaneoka H, Ohta N, Hayase R, Iwamoto I. Four common HLA haplotypes and their association with diseases in the Japanese population. Transplantation ProJapanese population. Trans

4 Juji T, Naohara T, Masuda $M$, Takahashi $K$. HLA antigens in Japanese patients with MCTD. In: Kasukawa R, Sharp G C, eds. Mixed connective tissue disease and anti nuclear antibodies. Amsterdam: Elsevier, 1987: 3-8.

5 Tan E M, Cohen A S, Fries J F, et al. The 1982 revised criteria for the classification of systemic lupus erythematosus. Arthritis systemic lupus erythema
Rheum 1982; 25: 1271-7.

6 Kàsukawa R, Tojo T, Miyawaki S, et al. Preliminary diagnostic criteria for classification of mixed connective tissue disease. In: Kasukawa R, Sharp G C, eds. Mixed connective tissue disease and antinuclear antibodies. Amsterdam: Elsevier, 1987: 41-7.

7 Notman D D, Kurata N, Tan E M. Profiles of antinuclear antibodies in systemic rheumatic diseases. Ann Intern Med 1975; 83: 464-69.

8 Alarcón-Segovia D, Cardiel M H. Comparison between diagnostic criteria for mixed between diagnostic criteria for mixed
connective tissue disease. Study of 593 connective tissue disease. Study of
patients. $\mathcal{f}$ Rheumatol 1989; 16: 328-34.

\section{Rice bodies in the pleural aspirate of a patient with rheumatoid arthritis}

Rice bodies (RB), aggregations of fibrin and cells so named because they resemble polished white rice, ${ }^{1}$ are common findings in the synovial fluid of rheumatoid arthritis (RA). ${ }^{2}$ Microscopically, RB vary in shape and size, some being so large as to preclude effective removal by routine needle aspiration. ${ }^{3}{ }^{4} \mathrm{RB}$ can occur at any time during the course of RA and are not related to the severity of clinical or radiological change, ${ }^{5}$ but removal of RB from a joint is accompanied by clinical improvement and reduction of synovitis. ${ }^{6} \mathrm{RB}$ have not previously been reported in other body fluids.

A woman of 56 who had suffered RA for 11 years presented with active systemic disease and serositis. Examination revealed a left sided pleural effusion, ulcerated rheumatoid nodules over both elbows and a moderate synovitis of both knees. Other joints showed only chronic deformity. Investigations showed hypochromic microcytic anaemia (Hb:8.3 g/dl, MCV:70 fl, MCH:19.7 pg), thrombocytosis (PLT: $637 \times 10^{9} / \mathrm{L}$ ), an acute phase response (CRP:79 mg/L, PV:1.93 $\mathrm{mPa}$ ) and evidence of circulating immune complexes (CIC) and complement consumption (RhF:2000 IU/ml, C4:0.1 g/L, $\mathrm{CH} 50<30$ units, $\mathrm{C} 1 \mathrm{q}$-binding $>80$ units).

A careful history did not reveal any other reason for this patient's anaemia. Investigations including upper and lower endoscopy were all normal. One month later her $\mathrm{Hb}$ had improved (Hb:9.6 g/dl, MCV:82 fl, MCH:23 $\mathrm{pg}$ ) in parallel with her disease activity.

Pleural and synovial fluids were each aspirated using the same size needle, that is, green $(21 \mathrm{~g})$ which is routinely used for these procedures in our practice. The figure shows copious RB present in the pleural fluid aspirate only (picture taken immediately after aspiration). Mycobacterial culture and a Mantoux test were negative. Biochemical analysis of the pleural aspirate revealed an exudate (protein $35 \mathrm{~g} / \mathrm{l}$ and a $\mathrm{RhF}$ of $1: 160$ ).
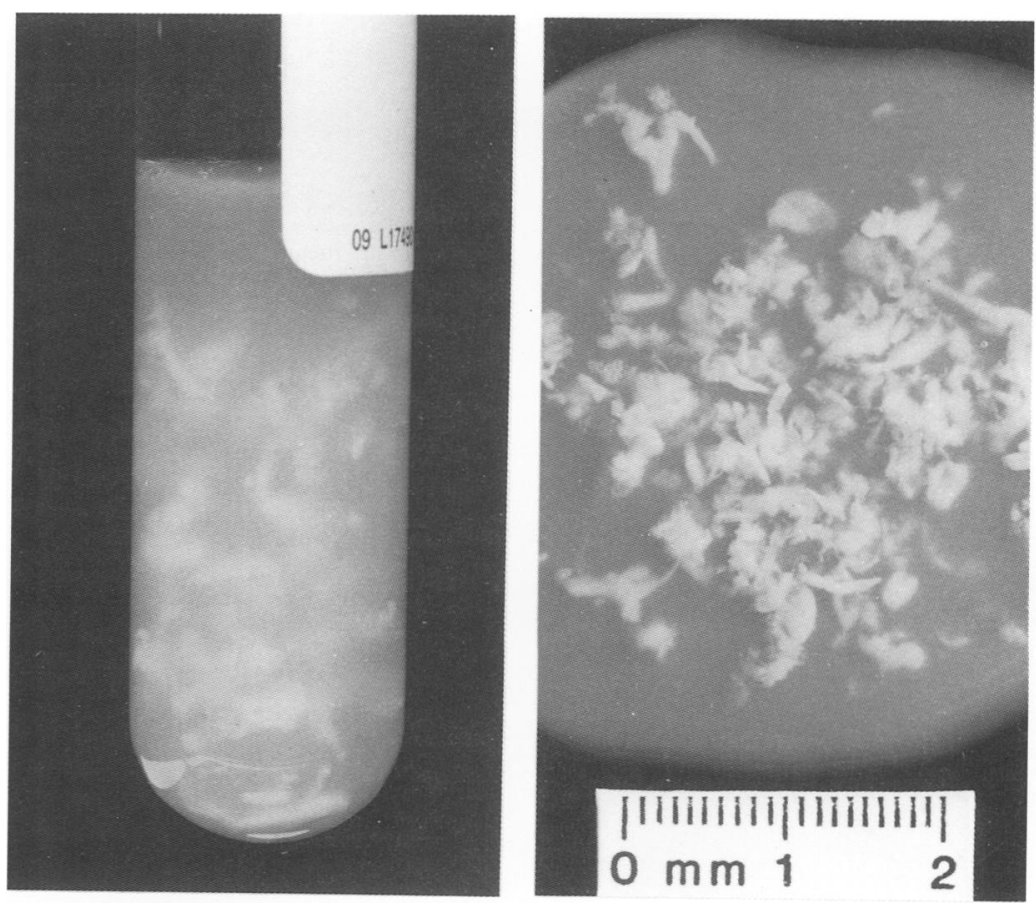

Copious $R B$ present in the pleural fluid aspirate (picture taken immediately after aspiration). 